\title{
Microalgae Strains Monoraphidium Griffithi and Chlorella sp. for the Carbon Dioxide Capture from Biogas
}

\author{
Loreta Juškaitè, Alvydas Zagorskis* \\ Faculty of Environmental Engineering, Vilnius Gediminas Technical University, Vilnius, Lithuania
}

Received 30 January 2020; accepted 06 February 2020

\begin{abstract}
One of the most important tools for mitigating climate change is biogas production. Increasing their use requires improving the energy value of biogas by reducing its carbon dioxide content while increasing the methane concentration in biogas. Biological purification of biogas using microalgae strains - merging biogas upgrading method where microalgae use carbon dioxide for their growth during the process of photosynthesis. A four-column photobioreactor was constructed with Monoraphidium Griffithi, Chlorella sp. microalgae strains, distilled water and MWH medium for purification of biogas. Experimental studies determined sizes, shapes and of microalgae cells, the pH changes of mediums used after biogas treatment and the composition of biogas before and after upgrading using photobioabsorber. Microalgae Monoraphidium Griffithi was estimated to have the greatest contribution to $\mathrm{CO}_{2}$ reduction by decreasing from $31.0 \%$ to $10.0 \%$. The smallest reduction in $\mathrm{CO}_{2}$ was recorded when biogas was flowing through $\mathrm{MWH}$ medium. Experiments have shown that the absorption of biogas components results in the release of oxygen. As the biogas was flowing through all suspensions, the oxygen concentration increased from 3.6 to $5.2 \%$.
\end{abstract}

Keywords: microalgae, biogas, photosynthesis, photobioabsorber, carbon dioxide, oxygen.

\section{Introduction}

Today, climate change is one of the most important global challenges that requires complex management, political and technological measures. Climate change is driven by greenhouse gas (GHG) emissions. Anaerobic digestion of organic waste is an important tool for mitigating climate change. The main components of biogas are methane (55-75\%), carbon dioxide (20-35\%), nitrogen (10\%) and hydrogen sulphide (3000-5000 ppm) and other impurities. In order to improve the energy value of biogas and to use it more efficiently, it is necessary to reduce its carbon dioxide, remove hydrogen sulphide and increase the total methane concentration in biogas.

Currently, the production of biogas by anaerobic treatment of sewage sludge is of particular interest. Sludge is divided into two main groups: primary (physically and / or chemically treated) and secondary (biological treated). Sometimes a tertiary type of sludge is also produced, which is obtained after additional removal of organic matter (Fytili \& Zabaniotou, 2008).

Biogas is produced from primary sludge. The yield of biogas depends not only on the technological process, but also on the composition of the organic raw material, especially nitrogen and phosphorus, fat and dry matter.

In Lithuania, as in the world, one of the most common sludge treatment methods is anaerobic sludge stabilization, which allows not only to reduce sludge content by up to $40 \%$ with respect to dry matter, but also to extract biogas, reduce pathogenic organisms, unpleasant odors (Vesilind, 2003; Pérez-Elvira et al., 2006). Methane accounts for more than $55 \%$ of the biogas produced and is therefore considered a valuable fuel that can be used in wastewater treatment plants and beyond, for example for electricity and heat production or as biofuel for transport (Budrys, 2006).

One of the main components of biogas from sewage sludge is carbon dioxide. Many different methods are used for purifying biogas from sewage sludge from carbon dioxide: physical absorption (with water), chemical absorption (with alkaline hydroxides, alkaline carbonates, ethanolamines) and others (with membranes, molecular filters) (Busca \& Pistarino, 2003), however, other researchers are increasingly reporting data on adsorption methods (dry decarbonisation, carbonization rocks) (Johnsen et al., 2006; Hildenbrand et al., 2006; Stasiulaitiené, 2010; Sherman \& Barak, 2000; Lackner et al., 1997).

The most widely used purification method is the physical/chemical absorption method as it requires less investment and is not complicated. The physical / chemical absorption method commonly involves high pressure and water

*Corresponding author. E-mail: alvydas.zagorskis@vgtu.lt 
absorber (Schieder et al., 2003; Rasi et al., 2008), where the cleaned biogas is fed into a purification column filled with Raschig rings, from below and using high pressure from above water.

Chemical absorption is determined by the reaction of $\mathrm{CO}_{2}$ with absorbence - ethanolamine, alkali, potash. The most common purification technology is chemical absorption using alkanolamines (monoethanolamine (MEA) and $\mathrm{N}$-methyl diethanolamine (MDEA) (Hoff et al., 2004)). Mo-noethanolamine solutions are widely used due to their properties: high efficiency, low cost and low uptake of hydrocarbons (Al-Marzouqi et al., 2008; Navaza et al., 2009; Fujii et al., 2009; Zaretskii et al., 2008).

Biological purification of biogas using microalgae strains is based on the principle of photosynthesis, in which microorganisms use carbon dioxide in the photobioreactor for their vital processes and reproduction. Correspondingly, the concentration of methane in biogas increases, and so does the energy value of biogas. At the same time, biogas from sulfur hydrogen and ammonia is purified. Improving the quality of biogas by using microalgae strains is based not only on biological processes but also on physical and absorption, where a significant reduction in carbon dioxide concentration is achieved by using an absorbent solution - water with chemical elements (MWH (Modified Woods Hole Medium)) with microalgae suspension (microalgae suspension)).

Biodegradation of micro-algae with biogas is not always considered to provide a high biogas upgration efficiency, so system design improvements, medium optimization and appropriate microalgae are constantly sought. High absorbency strains include Monoraphidium Griffithi microalgae found in fresh water. Microalgae use carbon dioxide to maintain their vital functions and benefit from the biogas treatment process. This removes harmful components from biogas and reduces the cost of biomass production (Hendroko et al., 2013).

Although considerable efforts have been made to develop efficient and cost-effective photobioreactors, the high cost of installing and operating artificial light sources in conventional photobioreactors with artificial lighting systems remains a major problem (Chen et al., 2011).

The light intensity decreases rapidly due to the shading of the light due to the increased concentration of both the cell and the product or the formation of biofilm on the surface of the reactor vessels (Chen et al., 2008). In addition, while short light paths are theoretically favorable for achieving high light efficiency, conventional light sources cannot come in close contact with microalgae culture as they typically emit large amounts of heat. Therefore, the light conversion efficiency of conventional photobioreactors is limited. Due to the problems and limitations associated with conventional light sources, various photobioreactor designs with different illumination strategies have been developed to increase microalgae growth rate and oil / lipid content (Ma \& Hanna, 1999).

As discussed above, the productivity of microalgae biomass production is often limited by the light energy supplied and the cell concentration.

A cost-effective, low-cost, durable, reliable, and highly efficient light source is required to produce a cost-effective unit. If the light source has a narrow spectral output that coincides with the absorption spectrum of photosynthesis, the emission of light at the wrong frequencies would be eliminated, thus improving overall energy conversion. Among the light sources currently available, LEDs are the only ones that meet the above criteria. Lightemitting diodes are light and small enough to fit in virtually any photobioreactor, with the other benefits of longer life, lower heat dissipation, higher conversion efficiency and tolerance on and off. In addition, LEDs have a narrow light emission spectrum of 20 to $30 \mathrm{~nm}$, which can be matched to the needs of photosynthesis. Wang et al. (2007) found that the highest specific growth rates and biomass production were obtained using a red light LED in a photobioreactor for growth of Spirulina platensis (Wang et al., 2007).

Significant research into the efficiency and applicability of bio-biogas purification methods has been carried out by scientists from different countries: Q. Zhao, R. Ramaraj, N. Dussadee, Y. Lee, G. Mann, M. Schlegel, R. Schumann, R. Sakalauskas, V. Makareviciene and others. Research findings and detailed results allow for an accurate assessment of not only the potential of efficient biological treatment methods, but also their realistic application, taking into account existing and expanding infrastructure in different countries.

The aim of the study was to evaluate the efficiency of carbon dioxide purification from biogas using Monoraphidium Griffithi and Chlorella sp. microalgae strains.

\section{Methodology}

Two cultures of microalgae strains of different genera were selected for the study: Chlorella sp. and Monoraphidium Griffithii.

Chlorella sp. belongs to the Chlorella family, a genus of Chlorella comprising about 56 species.

Monoraphidium Griffithii - spindle-shaped microalgae found in freshwater bodies. It is important to note that they need a sunlight or artificial light source to absorb carbon dioxide much more efficiently than plants do. These algae are used in the production of both biodiesel and bioethanol.

Knowing these microalgae evaluation criteria - size, shape and amount of microalgae cells - the volume of the biomass in suspension can be calculated, the changes in the life cycle (decay, death) of microalgae and the efficiency of carbon dioxide purification. 
Prior to conducting research on the shape, size and quantity of the microalgae cells, they were grown in an algae growth reactor at the Nature Research Center. The growth time of microalgae is 20-30 days.

The algae were grown at room temperature at $22 \pm 2{ }^{\circ} \mathrm{C}$ and illuminated with fluorescent lamps at $\sim 250 \mu \mathrm{mol} /$ $\mathrm{m}^{2} \mathrm{~s}$ white light for an average of $10 \mathrm{~h}$. per day. Light intensity was measured using a Data Logger (Model LI-1400) LI190SA Quantum sensor.

Microalgae cell shape, size and quantity were studied using a Nikon ECLIPSE Ci-L optical microscope. Microscope resolution $1 \mu \mathrm{m}$, magnification up to $600 \mathrm{x}$.

A microplate suspension of 256 cells is placed in a $0.0032 \mathrm{ml}$ glass slide. Cover the specimen with a lid, beginning with the tip of the drop and carefully lowering the slide to distribute the suspension evenly. Place the specimen on the stage and press it against the holders. Using the microscope levers, the image is focused. By changing the objective sample, the sample is magnified 200, 400 and 600 times and analyzed. The image is output to the screen. The number of microalgae cells in the selected cells is counted. By determining the amount of microalgae cells in the selected cells, the average number of cells per cell is derived. The value obtained is multiplied by the number of cells in the cell. In this way, the number of microalgae cells per unit cell of known volume is obtained.

The same micro-algae cultures are still being studied for carbon dioxide purification from biogas. Prior to the assays, microalgae were inoculated with biogenic elements in MWH medium (Modified Woods Hole MBL Medium) for 14 days. Oxygen was supplied to the microalgae suspension during inoculation.

The required volume of the microalgae suspension is 4 liters as this volume contains a photobioabsorber column. The microalgae biotope is diluted with the nutrient medium in such proportion that the chlorophyll content is the same in all microalgae suspensions. The initial concentration of chlorophyll is $516 \pm 10 \mathrm{mg} / 1$.

Before filling the columns with microalgae suspensions, measure the physico-chemical parameters of the suspensions: $\mathrm{pH}$, conductivity, Redox potential, TDS, total carbon, total organic carbon, inorganic carbon, total nitrogen concentration, chlorophyll concentration. In order to compare the effect of the nutrient medium and water on the purification of biogas from $\mathrm{CO}_{2}$, the two columns of the photobioabsorber are filled with these suspensions. Since the photobioabsorbent laboratory consists of four columns, the columns are filled with four suspensions for biogas purification: suspension with Monoraphidium Griffithii microalgae culture, suspension with Chlorella sp., microalgae culture, MWH nutrient medium, distilled water.

A laboratory bench and the course of the study were used for the studies.

The photobioabsorber constructed in the Department of Environmental Protection and Water Engineering of VGTU was used for the research. A schematic diagram of a photobioabsorber bench is shown in Figure 1.

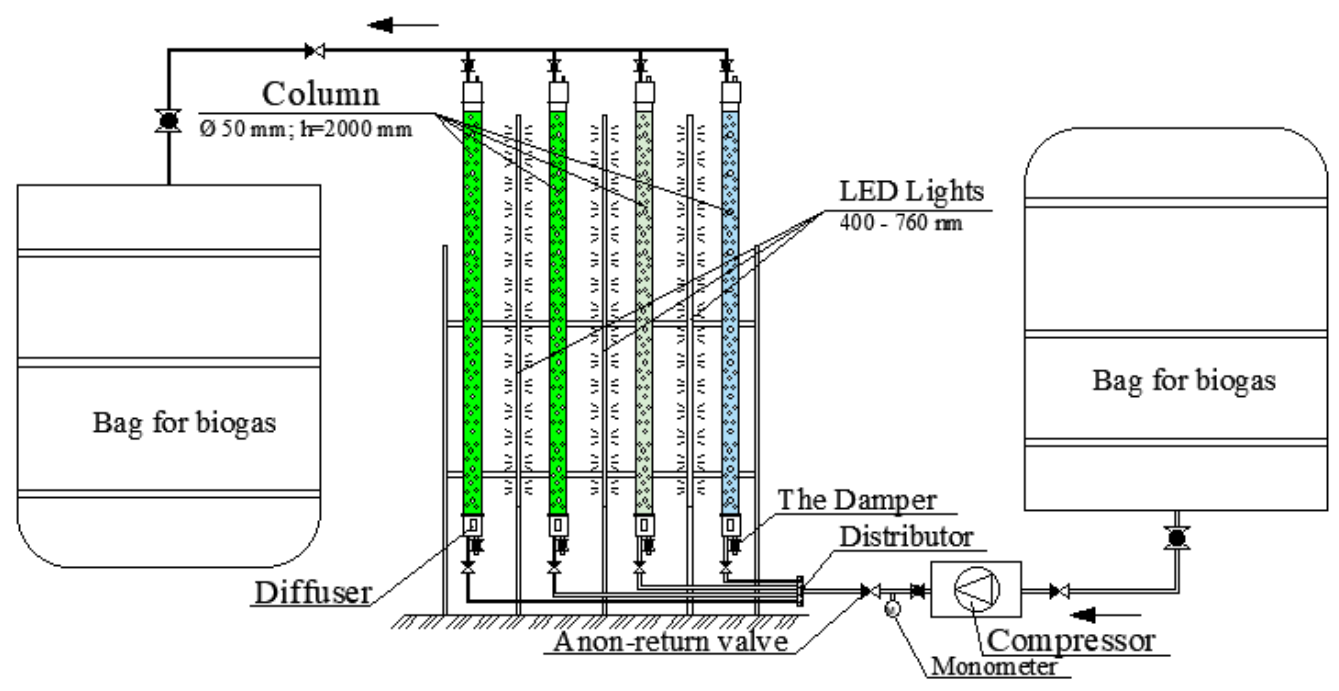

Figure 1. Photobioabsorber laboratory bench

Photobioabsorber - a microalgae strains filled biogas upgrading device to capture carbon dioxide from biogas, based on the principle of photosynthesis and absorption in liquid media.

From the $50 \mathrm{~L}$ biogas tank, the biogas obtained from the Vilnius sewage treatment plant is supplied by a compressor at a pressure of 200 mbar to four columns of 4 liters each. Each column is $2000 \mathrm{~mm}$ high and $50 \mathrm{~mm}$ in diameter. The distributor is equipped with valves that can regulate the flow of biogas into each column individually. Diffusers at the bottom of the column ensure uniform distribution of the biogas over the entire column cross-section, which disperses the biogas into small air bubbles, thereby improving the absorption and degradation of the elements contained in the biogas. The side illumination of the columns is equipped with LED light sources, which have regulators and the ability to select the required wavelength $(400-760 \mathrm{~nm})$ light. Biogas leaking columns are collected in a $2 \mathrm{~m}^{3}$ biogas collection tank. 
Biogas for research was taken from AB Vilniaus vandenys wastewater treatment plant. The biogas from the biogas storage tanks installed in the wastewater treatment plant is supplied by a compressor at a pressure of $100 \mathrm{mbar}$ to a biogas tank with a capacity of $50 \mathrm{~L}$. Composition of biogas taken from wastewater treatment plant: methane $51.5 \%$, carbon dioxide $31.0 \%$, oxygen $3.6 \%$, hydrogen sulfide 2 ppm.

From the biogas tank, the compressor passes the biogas through the suspension columns. The biogas is supplied to the photobioabsorbent at a flow rate of $0.2 \mathrm{~L} / \mathrm{min}$. The photobioabsorber columns are illuminated by a white light LED source. The LED source is positioned $200 \mathrm{~mm}$ from the column to ensure that the light flux is evenly distributed throughout the column surface. The light intensity is adjusted so that the sharpness level of the columns reaches 500 lx.

The image of the laboratory bench is shown in Figure 2.

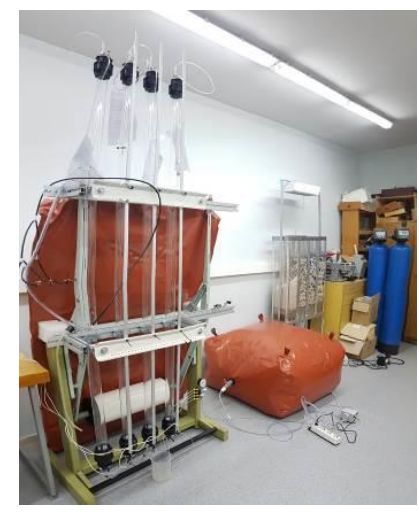

a)

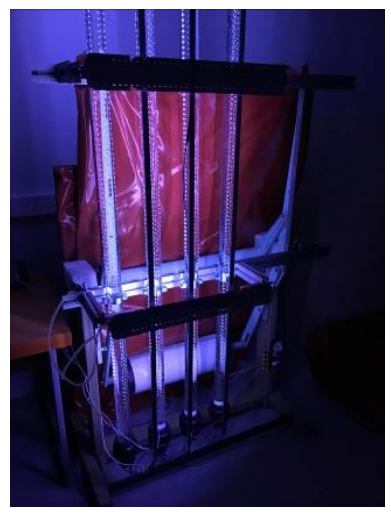

b)

Figure 2. Laboratory bench (photobioabsorber): a) general view; b) lighting system view

Biogas is passed through photobioabsorber columns for 10 days. The biogas composition is measured every 3 days before and after each column. A sample of $1 \mathrm{~L}$ Tedlar is taken from the sampling points in the bench before and after each column to determine the biogas composition. The physical and chemical parameters mentioned in Table 2.2 of the suspension are measured every 5 days. The suspension is sampled from a laboratory bench in a $50 \mathrm{ml}$ vial. The samples are transported in a mobile refrigerator for analysis to the laboratory of the Nature Research Center.

The dependence of the biogas cleaning efficiency on the suspension and the time of biogas passed through the photobioabsorber is investigated. This determines the dependence of the physico-chemical parameters of the suspensions on the time of biogas allowed through the photobioabsorber.

\section{Application of analytical methods}

The biogas composition was measured daily with the biogas analyzer INCA 4000, which provides methane (\%), carbon dioxide $(\%)$, oxygen $(\%)$ concentrations and hydrogen sulfide (ppm). Appliance measuring ranges: $0-25 \%$ oxygen ( $\pm 1 \%$ tolerance), hydrogen $0-100 \mathrm{ppm}$ hydrogen ( $\pm 5 \%$ tolerance), methane $0-100 \%$ ( $\pm 1 \%$ tolerance), carbon dioxide $-0-100$ ( $\pm 1 \%$ error $)$.

The $\mathrm{pH}$ is determined by a potentiometric method which is standardized. Measured according to LST ISO 10523: 1994. For $\mathrm{pH}$ determination, use the $\mathrm{pH}$ meter $\mathrm{HI} 98127$, which measures the $\mathrm{pH}$ of the solution (measuring range 0 to 14 , error $\pm 0,1$ ) and temperature (measuring range -5 to $60{ }^{\circ} \mathrm{C}, \pm 0,5^{\circ} \mathrm{C}$ ). The $\mathrm{pH}$ of the substrate is determined before and after the assay.

Illumination was measured using a meter Metrel Poly MI6401 with a measuring range (0 to 10.000) $1 x$.

Measurements were made in three replicates. After obtaining the results of tests for a given parameter, its estimate is calculated, which is the arithmetic mean of the individual measurements. Knowing the arithmetic mean of the parameter, the experimental dispersion corresponding to the probability distribution of individual measurements was calculated. By calculation is founded the best estimate of the arithmetic mean dispersion, which is the experimental mean arithmetic dispersion equal to the normal distribution. After obtaining the arithmetic mean dispersion estimate, the experimental standard deviation of the arithmetic mean was calculated:

Microsoft Office Excel 2003 was used for statistical calculations. Arithmetic averages of measurements, experimental arithmetic variances, standard deviations of arithmetic mean were calculated using Microsoft Office Excel 2003 Statistical functions: AVERAGE, VARP, STDEV (standard deviation).

\section{Results and discussion}

By increasing the sample size to 200, 400 and 600 times the morphological composition of the microalgae was determined. The morphological composition studies show that the structure of the microalgae is not uniform. Studies have 
shown that the microalgae examined are green in color due to their high chlorophyll content. Figure 3 shows the size and shape of the microalgae cultures Chlorella sp., Monoraphidium Griffithii when the biogas was not allowed through the microalgae suspension.

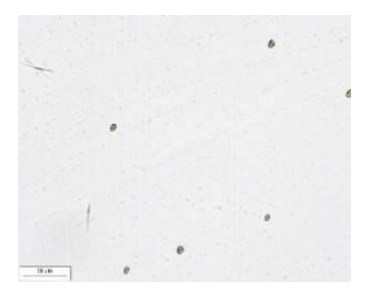

a)

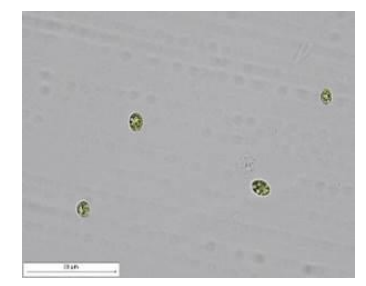

b)

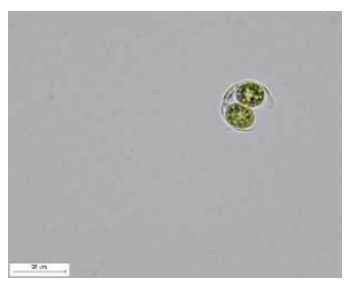

c)

Figure 3. Chlorella sp. microalgae size and shape:

a) magnification 200x; b) magnification 400x; c) magnification 600x

Figure 3 shows that Chlorella sp. cells of the genus Algae were single, spherical or elliptical, with studies measuring $10 \mu \mathrm{m}$ in diameter and $12 \mu \mathrm{m}$ in length. During the studies, the number of microalgae cells present in the biogas purification system before the suspension was 542060 cells / $\mathrm{ml}$.

Figure 4 shows that the microalgae of Monoraphidium Griffithii are elongated in shape. Consisting of two cells of equal size. The average cell length is $48 \mu \mathrm{m}$ and the diameter is $3.7 \mu \mathrm{m}$. The cell volume is $275 \mu \mathrm{m}^{3}$. The number of cells was 574320 cells / $\mathrm{ml}$.

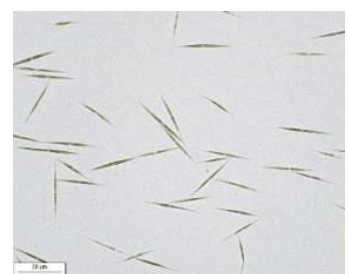

a)

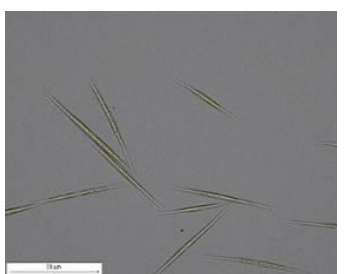

b)

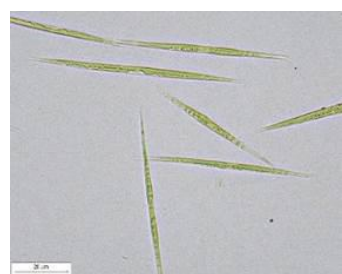

c)

Figure 4. Monoraphidium Griffithii microalgae size and shape:

a) magnification 200x; b) magnification 400x; c) magnification 600x

During the research, the $\mathrm{pH}$ and purification efficiency of biogas were investigated by passing biogas through photobioabsorber columns with different suspensions. In this way, the influence of different suspensions on the biogas composition was evaluated.

In order to determine how the $\mathrm{pH}$ of different suspensions changes through the biobleaching of the biogas produced by anaerobic digestion of sewage sludge, the $\mathrm{pH}$ concentration dependence of the duration of the biogas allowed through the photobioabsorbent was obtained when the photobioabsorber columns were filled with different compositions.

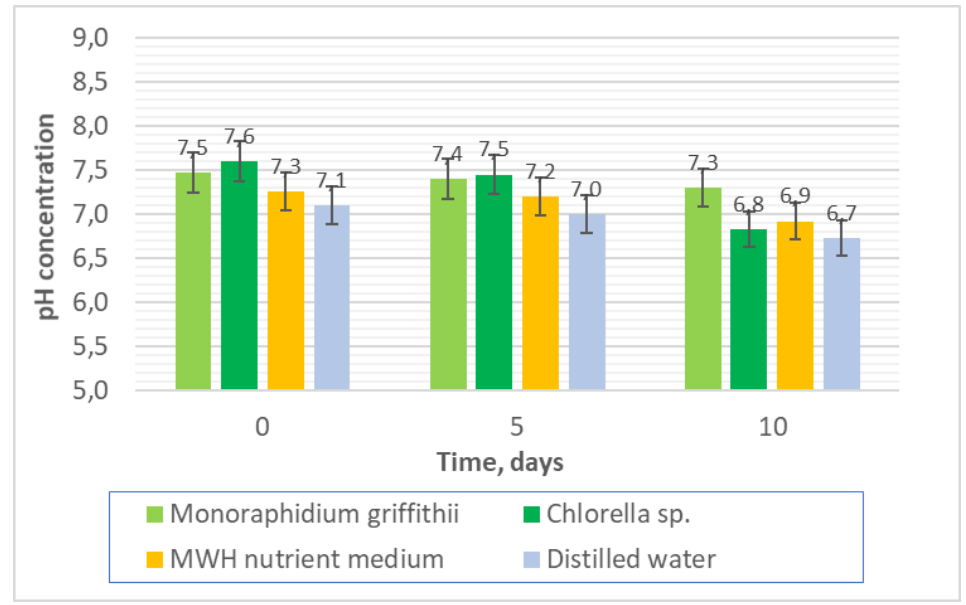

Figure 5. $\mathrm{pH}$ concentration dependence of biogas filtration time and different suspensions 
The first two columns are filled with Monoraphidium Griffithii and Chlorella sp. microalgae cultures. It is noteworthy that the concentration of chlorophyll in microalgae was uniform and reached $516 \pm 10 \mathrm{mg} / 1$. At this concentration, the $\mathrm{pH}$ of the microalgae suspension at the start of the study was 7.5 and 7.6, respectively (Figure 5). Also, in order to evaluate the absorption of biogas contaminants in liquid media without microalgae cultures, the remaining two photobioabsorbent columns were filled with MWH nutrient medium and distilled water at $\mathrm{pH} 7.3$ and 7.1, respectively.

Studies have shown that the $\mathrm{pH}$ of all suspensions is reduced by the passage of biogas through the photobioabsorber. The greatest decrease in $\mathrm{pH}$ after 10 days was observed in column-filled Chlorella sp. microalgae culture. After 10 days it reaches 6.8. The smallest reduction was found in column-filled culture of Monoraphidium Griffithii microalgae. Such acidification of the slurry is caused by chemical reactions of the compounds in the biogas, such as $\mathrm{CO}_{2}$ or $\mathrm{H}_{2} \mathrm{~S}$, with $\mathrm{H}_{2} \mathrm{O}$. This produces carbonic and sulfuric acids which also acidify the suspension itself. It is important to note that according to the literature, the $\mathrm{pH}$ of biogas is also acidic and averages between 6.6 and 6.8.

The initial methane concentration in the biogas was 51.5\% (Figure 6). After passage of the biogas through the suspension with Monoraphidium Griffithii microalgae culture, the methane concentration increased to 63.2\%. Between 5 and 10 days of biogas injection, the concentration of methane increased slightly, reaching $64.8 \%$. Lower methane concentrations were fixed by passage of biogas through suspension with Chlorella sp. microalgae culture. After 10 days the methane concentration increased to $63.2 \%$.

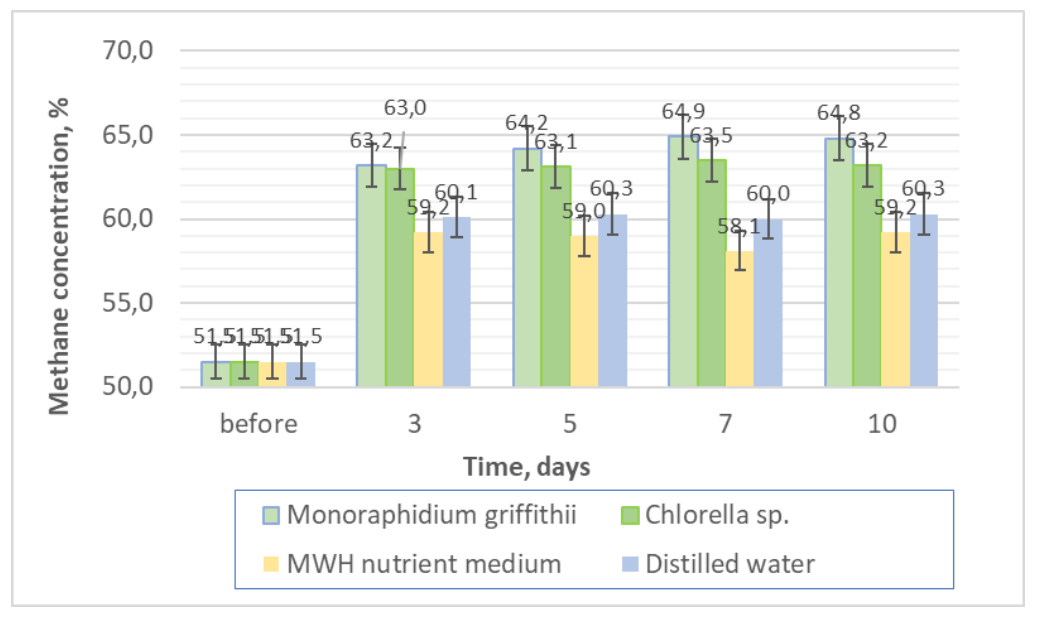

Figure 6. Methane concentration dependence on biogas flow time and different suspensions

It should be noted that the flow of biogas through distilled water increased the methane concentration to $59.2 \%$. We can assume that the increase in methane in the photobioabsorber is greatly influenced by the absorption processes taking place there. The solubility of carbon dioxide in water depends on its pressure and temperature. Microalgae increased the methane concentration to $64.8 \%$ after 10 days. Microalgae cultures contribute to improving the quality of biogas emitted by anaerobic treatment of sewage sludge. The methane concentration increased from $51.5 \%$ to $59.0 \%$ when biogas was injected via MWH medium. However, unlike suspensions with microalgae cultures, they remained stable.

Studies have shown that biogas, when passed through suspensions of the microalgae Monoraphidium Griffithii and Chlorella sp. in microalgae cultures, methane concentration increases. In the photobioabsorber, both absorption and biological purification methods have an effect on improving the quality of biogas.

Studies have also been carried out to evaluate the changes in carbon dioxide concentration in biogas as they pass through different suspensions (Figure 7). Studies have shown that the passage of biogas through all the suspensions studied decreases the concentration of carbon dioxide.

Studies have shown that passing biogas through distilled water reduced $\mathrm{CO}_{2}$ concentration from 31.0 to $13.7 \%$. With the release of biogas through distilled water over a longer period of 10 days, the $\mathrm{CO}_{2}$ concentration increases to $15.0 \%$. $\mathrm{CO}_{2}$ absorption decreases due to the reduced solubility of $\mathrm{CO}_{2}$ in the liquid medium. Biogas passage through micro-algae suspension slurries showed the greatest reduction in $\mathrm{CO}_{2}$. Microalgae culture of Monoraphidium Griffithii had the greatest impact on $\mathrm{CO}_{2}$ reduction. The passage of the biogas through the suspension with Monoraphidium Griffithii microalgae culture reduced the $\mathrm{CO}_{2}$ concentration from 31.0 to $12.7 \%$. Biogas flow through this suspension reduced the $\mathrm{CO}_{2}$ concentration to $10.0 \%$ for 10 days. The smallest reduction in $\mathrm{CO}_{2}$ was recorded when biogas was injected via $\mathrm{MWH}$ medium. Its effect on $\mathrm{CO}_{2}$ reduction was worst. 


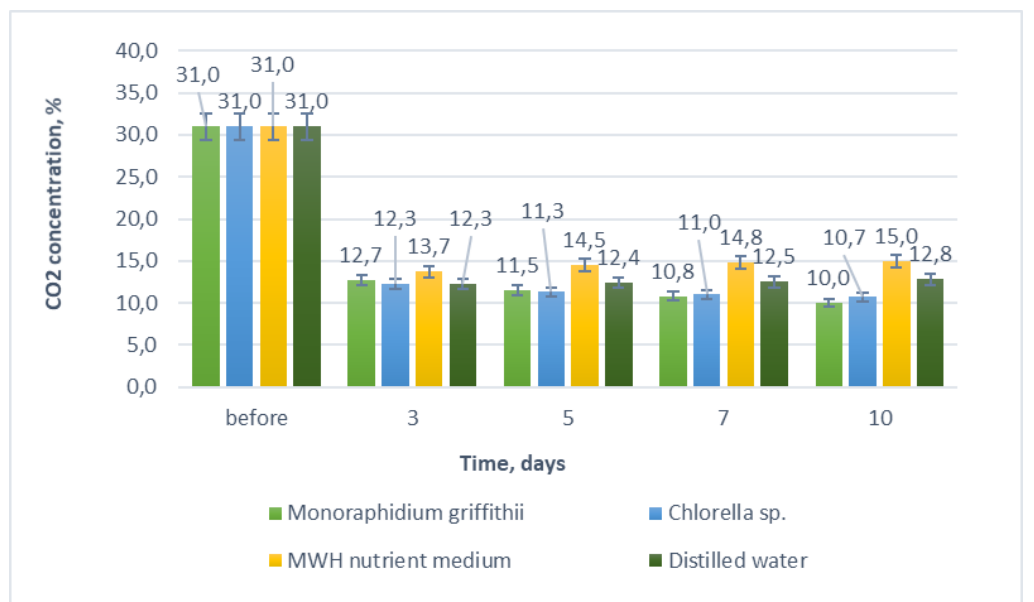

Figure 7. Dependence of carbon dioxide concentration on biogas flow time and different suspensions

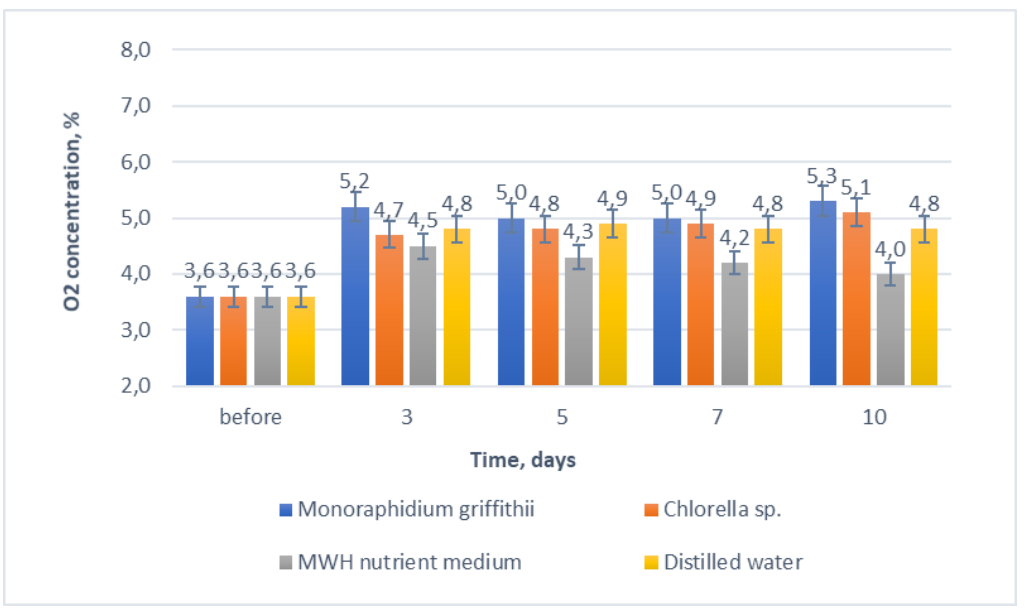

Figure 8. Dependence of oxygen concentration on biogas flow time and different suspensions

The reduction in $\mathrm{CO}_{2}$ and the high efficiency of its purification in biogas can be explained by the process of photosynthesis and absorption. The solubility of $\mathrm{CO}_{2}$ in water is higher compared to $\mathrm{CH} 4-1.45 \mathrm{~g} / 1$, which results in a higher proportion of $\mathrm{CO}_{2}$ being absorbed. Also, microorganisms such as algae are the gases needed to support vital functions during photosynthesis. During photosynthesis, microalgae are capable of synthesizing organic compounds from inorganic materials. Organic substances are synthesized from carbon dioxide and water and oxygen is released as a by-product. In this process, high-energy carbohydrate glucose is synthesized from low-energy materials, carbon dioxide and water (Zhao \& Su, 2014):

$$
\mathrm{CO} 2+\mathrm{H}_{2} \mathrm{O}=\mathrm{C} 6 \mathrm{H}_{12} \mathrm{O} 6+6 \mathrm{O}_{2} .
$$

Increased oxygen concentration in biogas indicates that $\mathrm{CO}_{2}$ absorption processes occur in suspensions (Figure 8).

During which the absorption of $\mathrm{CO}_{2}$ in the nutrient medium increases the concentration of oxygen. Microalgae cultures also increase concentration.

Studies have shown that the absorption of biogas components results in the release of oxygen. As the biogas was passed through all the suspensions, the oxygen concentration increased from 3.6 to $5.2 \%$. The highest concentration of oxygen was recorded by passage of biogas through suspension with micro-algae culture of Monoraphidium grffithii. The lowest concentration of oxygen $-4.5 \%$ - was recorded when biogas was injected via MWH medium. It is noteworthy that the oxygen concentration in the biogas increased during the 10-day passage of biogas through suspensions with microalgae cultures. This indicates that microalgae are active and capable of decomposing $\mathrm{CO}_{2}$ by releasing oxygen. At this interval, the oxygen concentration did not change or decrease after 10 days passage through distilled water and MWH nutrient medium. This reflects the reduced absorption of biogas components in these suspensions. 


\section{Conclusions}

1. Studies have shown that the $\mathrm{pH}$ of all suspensions is reduced by the flow of biogas through the photobioabsorber. The greatest drop in $\mathrm{pH}$ was found in column-filled Chlorella sp. microalgae culture (pH 7.6 to 6.8). The smallest reduction was found in column-filled culture of Monoraphidium Griffithii microalgae.

2. Methane concentration increased from $51.5 \%$ to $63.2 \%$ in the first 3 days after biogas treatment with Monoraphidium Griffithi microalgae. Such changes may have been caused by the absorption of $\mathrm{CO}_{2}$ in biotechnology.

3. Biogas flow through suspension with Chlorella sp. microalgae after 10 days, the concentration of methane increased from $51.5 \%$ to $63.2 \%$. The flow of biogas through distilled water increased the methane concentration to $59.2 \%$. Therefore, the increase in methane in the photobioabsorber is greatly influenced by the absorption processes taking place there.

4. Studies have shown that the flow of biogas through distilled water reduced $\mathrm{CO}_{2}$ concentration from $31.0 \%$ to $13.7 \%$. After 10 days of biogas, the $\mathrm{CO}_{2}$ concentration increases to $15.0 \%$. $\mathrm{CO}_{2}$ absorption decreases due to the reduced solubility of $\mathrm{CO}_{2}$ in the liquid medium.

5. Microalgae culture of Monoraphidium grffithii had the greatest impact on $\mathrm{CO}_{2}$ reduction. The flow of biogas through the suspension with this culture reduced the $\mathrm{CO}_{2}$ concentration from 31.0 to $10.0 \%$. The smallest reduction in $\mathrm{CO}_{2}$ was recorded when biogas was injected via $\mathrm{MWH}$ medium.

6. Studies have shown that the absorption of biogas components results in the release of oxygen. As the biogas was passed through all the suspensions, the oxygen concentration increased from 3.6 to $5.2 \%$. The highest concentration of oxygen was recorded by passage of biogas through suspension with micro-algae culture of Monoraphidium Griffithii. The lowest concentration of oxygen $-4.5 \%$ - was recorded when biogas was injected via MWH medium.

\section{References}

Al-Marzouqi, M., El-Naas, M., Marzouk, S., \& Abdullatif, N. (2008). Modeling of chemical absorption of $\mathrm{CO}_{2}$ in membrane contactors. Separation and Purification Technology, 62(3), 499-506. https://doi.org/10.1016/j.seppur.2008.02.009

Budrys, R. (2006). Nuotekų valymo dumblų (NVD) ir biodegraduojančių (BDA) atliekų tvarkymas. Iš 9-osios Lietuvos jaunuju mokslininkų konferencijos ,,Mokslas - Lietuvos ateitis “, įvykusios 2006 m. kovo 30 d., pranešimų medžiaga.

Busca, G., \& Pistarino, C. (2003). Technologies for the abatement of sulphide compounds from gaseous streams: a comparative overview. Journal of Loss Prevention in the Process Industries, 16(5), 363-371. https://doi.org/10.1016/S0950-4230(03)00071-8

Chen, C. Y., Saratale, G. D., Lee, C. M., Chen, P. C., \& Chang, J. S. (2008). Phototrophic hydrogen production in photobioreactors coupled with solar-energy-excited optical fibers. International Journal of Hydrogen Energy, 33(23), 6886-6895. https://doi.org/10.1016/j.ijhydene.2008.09.014

Chen, C. Y., Yeh, K. L., Aisyah, R., Lee, D. J., \& Chang, J. S. (2011). Cultivation, photobioreactor design and harvesting of microalgae for biodiesel production: a critical review. Bioresource Technology, 102(1), 71-81. https://doi.org/10.1016/j.biortech.2010.06.159

Fujii, T., Sugai, Y., Sasaki, K., \& Hashida, T. (2009). Measurements of $\mathrm{CO}_{2}$ sorption on rocks using a volumetric technique for $\mathrm{CO}_{2}$ geological storage. Energy Procedia, 1(1), 3715-3722. https://doi.org/10.1016/j.egypro.2009.02.170

Fytili, D., \& Zabaniotou, A. (2008). Utilization of sewage sludge in EU application of old and new methods - a review. Renewable and Sustainable Energy Reviews, 12(1), 116-140. https://doi.org/10.1016/j.rser.2006.05.014

Hendroko, R., Salafudin, Wahono, S. K., Wahyudi, A., Salundik, Praptiningsih, G. A., \& Liwang, T. (2013, July 12-13). Preliminary studies on biological purification system: integrated biogas from small anaerobic digestion and natural microalgae. In The $2^{\text {nd }}$ Natural Pigments Conference for South East Asia (NP-SEA). R\&D Center Universitas Ma Chung Malang.

Hildenbrand, N., Readman, J., Dahl, I. M., \& Blom, R. (2006). Sorbent enhanced steam reforming (SESR) of methane using dolomite as internal carbon dioxide absorbent: Limitations due to $\mathrm{Ca}(\mathrm{OH})_{2}$ formation. Applied Catalysis A: General, 303(1), 131-137. https://doi.org/10.1016/j.apcata.2006.02.015

Hoff, K. A., Juliussen, O., Falk-Pedersen, O., \& Svendsen, H. F. (2004). Modeling and experimental study of carbon dioxide absorption in aqueous alkanolamine solutions using a membrane contactor. Industrial \& Engineering Chemistry Research, 43(16), 4908-4921. https://doi.org/10.1021/ie034325a

Johnsen, K., Ryu, H. J., Grace, J. R., \& Lim, C. J. (2006). Sorption-enhanced steam reforming of methane in a fluidized bed reactor with dolomite as CO2-acceptor. Chemical Engineering Science, 61(4), 1195-1202. https://doi.org/10.1016/j.ces.2005.08.022

Lackner, K. S., Butt, D. P., \& Wendt, C. H. (1997). Progress on binding $\mathrm{CO}_{2}$ in mineral substrates. Energy Conversion and Management, 38, S259-S264. https://doi.org/10.1016/S0196-8904(96)00279-8

Ma, F., \& Hanna, M. A. (1999). Biodiesel production: a review. Bioresource Technology, 70(1), 1-15. https://doi.org/10.1016/S0960-8524(99)00025-5

Mann, G., Schlegel, M., Schumann, R., \& Sakalauskas, A. (2009). Biogas-conditioning with microal-gae. Agronomy Research, 7(1), 33-38.

Navaza, J. M., Gómez-Díaz, D., \& La Rubia, M. D. (2009). Removal process of $\mathrm{CO}_{2}$ using MDEA aqueous solutions in a bubble column reactor. Chemical Engineering Journal, 146(2), 184-188. https://doi.org/10.1016/j.cej.2008.04.040 
Pérez-Elvira, S. I., Diez, P. N., \& Fdz-Polanco, F. (2006). Sludge minimisation technologies. Reviews in Environmental Science and Bio/Technology, 5(4), 375-398. https://doi.org/10.1007/s11157-005-5728-9

Rasi, S., Läntelä, J., Veijanen, A., \& Rintala, J. (2008). Landfill gas upgrading with countercurrent water wash. Waste Management, 28(9), 1528-1534. https://doi.org/10.1016/j.wasman.2007.03.032

Schieder, D., Quicker, P., Schneider, R., Winter, H., Prechtl, S., \& Faulstich, M. (2003). Microbiological removal of hydrogen sulfide from biogas by means of a separate biofilter system: experience with technical operation. Water Science and Technology, 48(4), 209-212. https://doi.org/10.2166/wst.2003.0256

Sherman, L. A., \& Barak, P. (2000). Solubility and dissolution kinetics of dolomite in $\mathrm{Ca}-\mathrm{Mg}-\mathrm{HCO}_{3} / \mathrm{CO}_{3}$ solutions at $25^{\circ} \mathrm{C}$ and 0.1 MPa carbon dioxide. Soil Science Society of America Journal, 64(6), 1959-1968. https://doi.org/10.2136/sssaj2000.6461959x

Stasiulaitienė, I. (2010). Sukoncentruoto anglies dioksido surišimo Lietuvos uolienomis galimybès (Daktaro disertacija). Kaunas.

Vesilind, P. (Ed.). (2003). Wastewater treatment plant design (Vol. 2). IWA Publishing.

Wang, C. Y., Fu, C. C., \& Liu, Y. C. (2007). Effects of using light-emitting diodes on the cultivation of Spirulina platensis. Biochemical Engineering Journal, 37(1), 21-25. https://doi.org/10.1016/j.bej.2007.03.004

Zaretskii, M. I., Rusak, V. V., \& Chartov, E. M. (2008). Removal of acidic impurities from gases by absorption using monoethanolamine: A review. Coke and Chemistry, 51(11), 457-458. https://doi.org/10.3103/S1068364X08110082

Zhao, B., \& Su, Y. (2014). Process effect of microalgal-carbon dioxide fixation and biomass production: a review. Renewable and Sustainable Energy Reviews, 31, 121-132. https://doi.org/10.1016/j.rser.2013.11.054 